\title{
O ENSINO DE ENFERMAGEM OBSTETRICA PARA ESTUDANTES MASCULINOS
}

\author{
“Atrair estudantes do sexo masculi- \\ no para enfermagem é um problema; fa- \\ zer uma educação igual a de suas cole- \\ gas é outro" * \\ Nilza Tereza Rotter Pelá ** \\ Diva Mercedes Imperatriz * *

\section{INTRODUÇÃO}

0 ensino de enfermagem para estudantes de ambos os sexos tem sido igual em quase todas as especialidades, excetuando-se enfermagem obstétrica. Essa exceção é devida à rígida tradição de ensino de enfermagem, onde somente mulheres podem prestar cuidados no ciclo grávido-puerperal. Alegam os opositores a esse ensino aos estudantes do sexo masculino que, além de ser desnecessário, é muito embaraçoso para as pacientes.

Um estabelecimento no Canadá (1), onde estudantes de enfermagem do sexo masculino prestam cuidados de enfermagem a mulheres no ciclo grávido-puerperal, as pacientes mostraram-se satisfeitas e afirmaram que isso não é mais embaraçoso que os exames médicos.

Através de contato com vários docentes de enfermagem obstétrica, observa-se que o ensino dessa disciplina, para estudantes masculinos, é assunto que tem suscitado opiniões não só diferentes, mas também antagônicas. Para alguns, esse ensino é desnecessário e para outros, é imprescindível.

Daí surgiu a idéia de se coletar informações dos docentes de enfermagem obstétrica de diversas escolas de enfermagem do País.

(*) Why not Obstetric Nursing for Male Students. The Canadian Nursing. Vol. 62, n.9 10, pág. 40-41, oct. 1966.

$\left(^{\star \star *}\right)$ Auxiliares de ensino da disciplina de Enfermagem Obstétrica e Ginecológica da Escola de Enfermagem de Ribeirão Preto-USP. 
Pareceu útil, também, conhecer a opinião de profissionais em enfermagem do sexo masculino (enfermeiros e auxiliares), formados pela Escola de Enfermagem de Ribeirão Preto, USP, onde o ensino da disciplina enfermagem obstétrica, desde 1965, tem sido sistematicamente dado aos estudantes de ambos os sexos.

\section{OBJETIVOS}

O presente levantamento foi proposto com os seguintes objetivos:

1 - obter informações de cursos e escolas do País, nos três níveis profissionais, quanto ao ensino da disciplina de enfermagem obstétrica aos estudantes do sexo masculino;

2 - conhecer as justificativas desses cursos e escolas, para a omissão ou forma de ensino dessa disciplina, em relação a este tipo de estudantes;

3 - saber as opiniões de profissionais de enfermagem (enfermeiros e auxiliares) do sexo masculino, formados pela Escola de Enfermagem de Ribeirão Preto-USP, sobre a utilidade, durante o exercício profissional, do aprendizado da referida disciplina que tiveram quando estudantes.

\section{MATERIAL E METODO}

\section{População}

A amostra constou de:

1 - setenta e três escolas que ministrassem um, dois ou os três tipos de cursos. (A lista dessas escolas foi fornecida pela Associação Brasileira de Enfermagem em 1969);

2 - dois enfermeiros e onze auxiliares de enfermagem, formados pela Escola de Enfermagem de Ribeirão Preto-USP, desde 1965 a 1969 .

\section{TECNICA}

Utilizou-se para a obtenção de dados a técnica de questionário. Foram enviados dois questionários diferentes:

1 - um, às escolas mencionadas, a fim de coletar dados referentes aos dois primeiros objetivos;

2 - outro, aos profissionais citados, a fim de atingir ao terceiro objetivo. 


\section{RESULTADOS}

Dos setenta e três questionários enviados às escolas, obteve-se respostas de 83 cursos, sendo $28(32,6 \%)$ de enfermagem, $5(5,8 \%)$ de técnico de enfermagem e $53(61,6 \%)$ de auxiliar de enfermagem.

A maioria dos cursos que respondeu, estava situada no sudeste. Nesta região encontravam-se $53,6 \%$ dos cursos de enfermagem; $60,0 \%$ dos de técnico e $45,3 \%$ dos de auxiliar. A seguir, veio a região nordeste com $25,0 \%$ dos cursos de graduação, $20,0 \%$ dos de técnico e $22,6 \%$ dos de auxiliar. A região sul apresentou o percentual de $14,3 \%$ dos cursos de enfermagem; $20,0 \%$ dos de técnicos e $22,6 \%$ dos de auxiliar. Da região norte obteve-se respostas de cursos de graduação e auxiliar com os seguintes percentuais: 7,1\% dos cursos de graduação e $3,8 \%$ dos de auxiliar. A região centro-oeste aparece com $5,7 \%$ dos cursos de auxiliar.

Esses cursos de orientação leiga ou religiosa, eram particulares ou governamentais. $61,2 \%$ dos cursos eram de orientação leiga e destes $24,6 \%$, particulares e $36,6 \%$ governamentais. Os $38,8 \%$ cursos restantes eram de orientação religiosa, sendo que $34,8 \%$ eram particulares e $4,0 \%$ governamentais.

Pelas respostas obtidas verificou-se que os cursos tinham, não tinham e não recebiam estudantes do sexo masculino.

O não recebimento deste tipo de estudantes foi encontrado, nos cursos de graduação, técnico e auxiliar, com os percentuais de $3,6 \%, 20,0 \%$ e $9,4 \%$ respectivamente.

Não tinham estudantes do sexo masculino $17,8 \%$ dos cursos de enfermagem, $\mathbf{4 0 \%}$ dos de técnico e $\mathbf{7 , 6 \%}$ dos de auxiliar.

Recebiam e tinham estudantes do sexo masculino $\mathbf{7 8 , 6 \%}$ dos cursos de enfermagem, $\mathbf{4 0 , 0 \%}$ dos de técnico e $\mathbf{8 3 , 0 \%}$ dos de auxiliar. Dentre estes últimos, a disciplina de enfermagem obstétrica era ministrada de forma teórica ou teórica-prática aos estudantes do sexo masculino.

Dos cursos de enfermagem que possuíam estudantes do sexo masculino, $23,8 \%$ ofereciam a estes apenas o ensino teórico e $76,2 \%$, o teórico-prático. Em 50\% dos cursos técnicos, o ensino era teórico e em $50,0 \%$, prático. Na maioria $(62,5 \%)$ dos cursos de auxiliar, o ensino para os referidos estudantes era só teórico e para $37,5 \%$, teórico-prático.

Embora os cursos tenham mencionado experiência prática, esta não era dada em todas as unidades, conforme pode-se observar na Tabela $I$. 


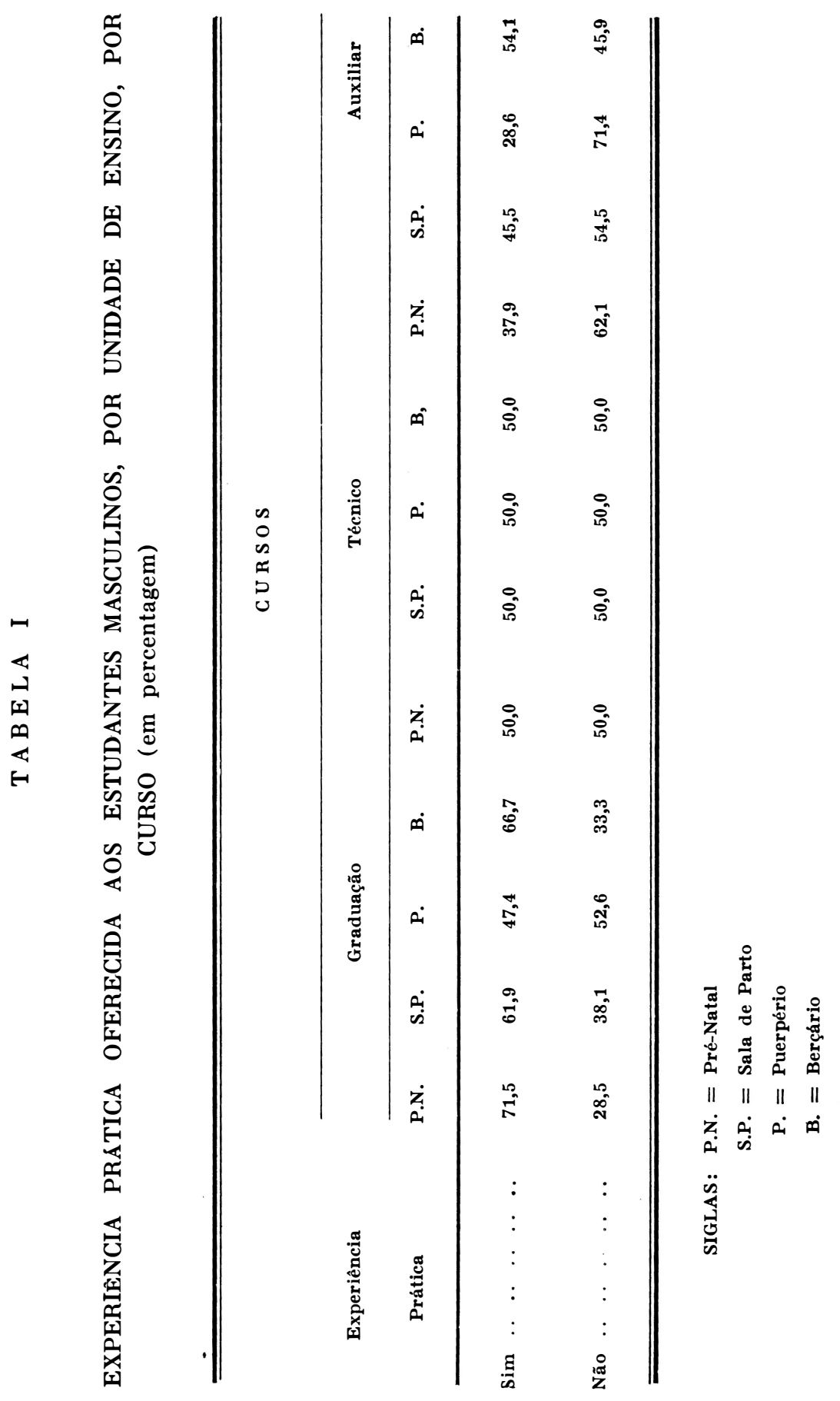


Dentre os cursos que ofereciam experiência em sala-de-parto, encontrou-se que esta, para alguns cursos, não englobava a assistência ao parto e nem o cuidado de enfermagem à parturiente.

Dos cursos de enfermagem que proporcionam essa experiência em sala-de-parto, $66,7 \%$ permitem aos estudantes do sexo masculino cuidar da parturiente e prestar assistência ao parto e 33,3\% não o permitem. Em 50,0\% dos cursos técnicos há esta permissão e em $50,0 \%$ não há. Um alto percentual $(90,0 \%)$ de não permissão dessas atividades foi encontrado nos cursos de auxiliar.

B - Respostas dos questionários enviados aos profissionais de enfermagem.

Foram enviados questionários a onze auxiliares de enfermagem e a dois profissionais de enfermagem do sexo masculino, formados pela Escola de Enfermagem de Ribeirão Preto, onde o curso teórico-prático de enfermagem obstétrica tem sido sistematicamente dado, desde 1965, a estudantes de ambos os sexos.

Dos onze questionários enviados a auxiliares de enfermagem, recebeu-se sete respostas; os dois enfermeiros, incluídos na amostra, responderam o questionário.

As respostas da pergunta referente à "necessidade que tiveram os enfermeiros e auxiliares de enfermagem de prestar cuidados de enfermagem a gestantes, parturientes e puérperas" foram:

- positiva de um enfermeiro para os três tipos de pacientes, e outro enfermeiro respondeu positivamente para gestante e negativamente para parturiente e puérpera. Dos sete auxiliares, seis responderam positivamente e um negativamente para gestantes; para parturiente e puérpera os sete responderam positivamente.

A pergunta: "durante sua vida de profissional, sentiu necessidade de utilizar seus conhecimentos de enfermagem obstétrica?" Os dois enfermeiros e os sete auxiliares de enfermagem responderam positivamente.

A pergunta: “agora, que já tem experiência profissional, você acha que os rapazes devam ter experiência prática (estágio) de obstetrícia durante o curso?" Foi respondida positivamente pelos dois enfermeiros e os sete auxiliares.

\section{DISCUSSÃO}

Aqui, tentar-se-á, analisar os resultados obtidos, na seguinte ordem :

1 - os cursos que não têm, ou não recebem, estudantes masculinos; 
2 - os cursos que têm estudantes masculinos. Dentre estes, estudar-se-á as razões que os levaram a permitir, ou não, a participação destes estudantes, na prática; fermagem.

3 - a opinião dos profissionais, do sexo masculino, de en-

Analisando-se o fato, "não terem ou não receberem" estudantes masculinos, relacionou-se esses cursos com sua orientação leiga ou religiosa e sua localiżação geográfica. Encontra-se na Tabela II o relacionamento entre o tipo de curso, sua orientação leiga ou religiosa e sua localização geográfica.

\section{T A B E L A I I}

CURSOS DE GRADUAÇÃO, DE TÉCNICO E DE AUXILIAR DE ENFERMAGEM NÃO TEM OU NÃO RECEBEM ESTUDANTES MASCULINOS, DE ACORDO COM SUA LOCALIZACCÃO E ORIENTA ÇÃO LEIGA OU RELIGIOSA (EM PORCENTAGEM)

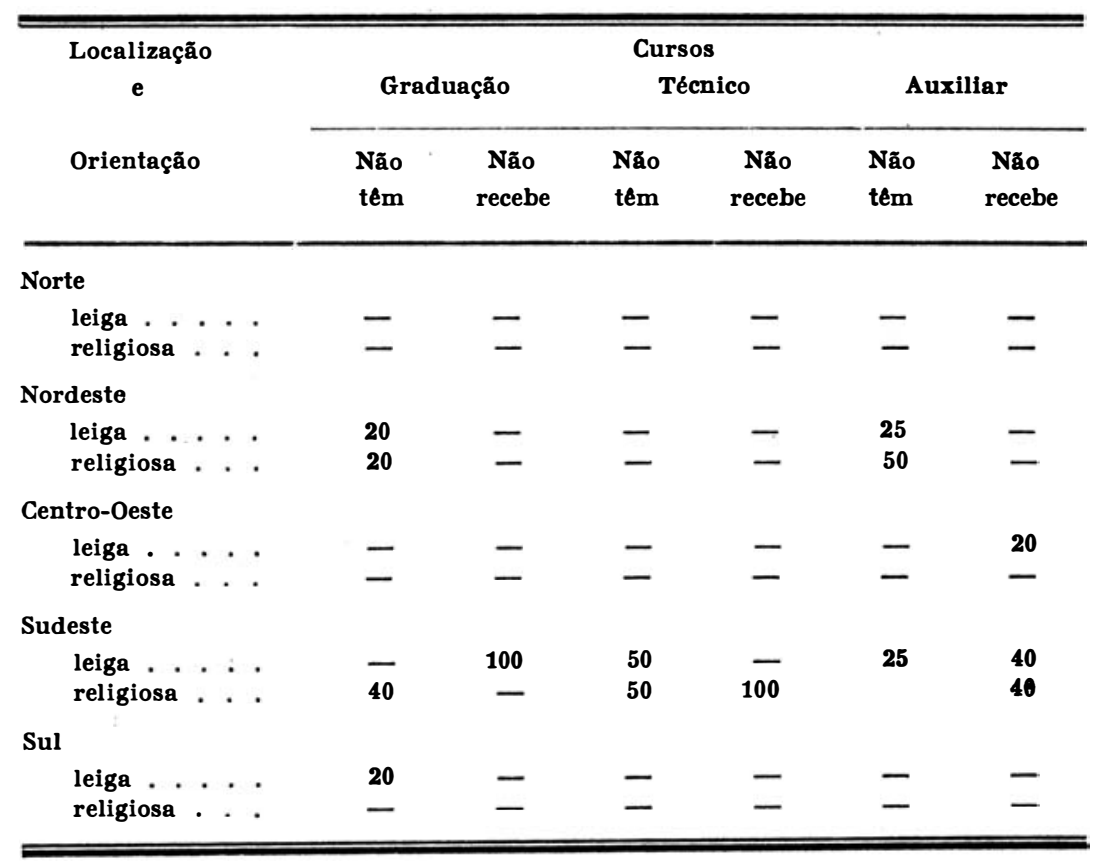

Observando-se a tabela acima, vê-se que não há relação entre a orientação leiga ou religiosa das escolas e o fato destas "não terem ou não receberem" estudantes do sexo masculino. 
Está localizado no Sudeste o maior número de cursos que não tem ou não recebe estudantes do sexo masculino; isto pode ocorrer devido:

- haver nessa região maior número de cursos;

- ser uma região onde há maior desenvolvimento econômico e industrial, com maior número de escolas de profissões tipicamente masculinas, com correspondente mercado de trabalho.

Os cursos que recebem estudantes do sexo masculino apresentam três tendências em relação ao ensino de enfermagem obstétrica para estes alunos, quais sejam:

- que eles devam receber o ensino teórico-prático;

- que só o ensino teórico basta;

- que eles não. necessitam do ensino desta disciplina.

E no Curso de Auxiliar de Enfermagem onde incide a maior porcentagem $(62,5 \%)$ de cursos que só ministram o ensino teórico. A situação inverte-se no curso de graduação onde a maioria dos cursos $(\mathbf{7 6 , 2 \% )}$ ministra o ensino teórico-prático. Para o curso de técnico de enfermagem, a proporção entre o ensino teórico e teórico-prático é igual

Isso pode ser devido ao nível cultural dos alunos, nos diferentes cursos e a perspectiva que os docentes têm do mercado de trabalho para os diferentes profissionais. Poder-se-ia, também, sob esse aspecto, lembrar-se da facilidade que teria o docente de suprimir parte do curriculum geral ao estudante do nível médio, porque este apresenta-se mais submisso à autoridade escolar, enquanto o estudante universitário é mais exigente.

Outra razão que pode ser mencionada é a Portaria n. ${ }^{\circ} 106$, de 28 de abril de 1965, que permite aos cursos de auxiliar de enfermagem optar entre ministrar ou não o ensino de enfermagem obstétrica aos estudantes do sexo masculino, substituindo a referida disciplina por enfermagem urológica.

Dentre as justificativas, apresentadas pelas escolas para não ministrarem o ensino prático de enfermagem obstétrica, as mais citadas foram: masculino;

- o diretor da maternidade não aceita estudantes do sexo

- esses estudantes não são aceitos pelas pacientes;

- o regimento interno da escola dispensa cu não permite aos estudantes do sexo masculino a prática nessa disciplina; 
- a Portaria n. ${ }^{\circ} 106$, de 28 de abril de 1965;

-. a disciplina não tem utilidade, na vida profissional.

As menos citadas foram:

- o estudante do sexo masculino prejudica o serviço;

- enfermagem obstétrica é afazer de mulher;

- não há consumo profissional;

- a "moral" da escola não permite;

- os estudantes do sexo masculino não têm condições sócio-culturais (mencionada para o curso de auxiliar de enfermagem); culino.

- a prática é "inconveniente" para estudantes do sexo mas-

Dentre os motivos mencionados pelas escolas que ministram o ensino teórico-prático da disciplina, os mais freqüentes foram:

- preparar estudantes para atuar em situações de urgência;

- a realidade nacional necessita de profissionais com formação global em enfermagem;

- estudantes do sexo masculino são pais em potencial;

- os estudantes do sexo masculino do Curso de Graduação têm o mesmo "padrão" que os de Medicina; mulheres;

— os estudantes são moralmente preparados para cuidar de

- quando os estudantes são bem orientados, eles e as pacientes aceitam-se mutuamente.

Pelo exposto vê-se que muitas das justificativas apresentadas para ministrar ou não a experıencia prática na disciplina de enfermagem obstétrica se contradizem.

Os motivos mais levantados para a ausência da prática referem-se a situações locais (diretores das maternidades não aceitam) e à tradição (pacientes não aceitam). Esses dois motivos não justificam a ausência da prática, pois requer melhor investigação nesta área, a fim de verificar-se se as pacientes realmente a rejeitam e os motivos pelos quais os diretores não a aceitam. Pode-se pensar que a tradição existente, ligando o cuidado de enfermagem das pacientes no ciclo grávido-puerperal ao atendimento de profissionais de sexo feminino, seja o fator mais importante nessa situação.

Mais uma vez, levanta-se o problema do não ministrar a parte prática desta disciplina que merece maiores investigações, pois as 
razões apontadas para esse ensino são racionais e estão dentro da realidade vigente, enquanto que as razões para a omissão do ensino não têm a mesma lógica, parecendo estar ligada a preconceitos culturais.

Os argumentos dados para justificar o ensino prático de enfermagem obstétrica aos estudantes do sexo masculino baseiam-se, principalmente, no fato de que situações de urgência podem ocorrer em qualquer lugar. O profissional de enfermagem, seja do sexo feminino ou masculino, é aquele mais bem preparado para atender tais situações.

Outra justificativa está no fato de que o enfermeiro e o auxiliar orientam os atendentes, que constituem a maioria do pessoal de enfermagem (2). Sendo um orientador, deve ter formação global.

Ademais, todo indivíduo deve estar preparado para suas responsabilidades familiares e comunitária.

As razões emitidas pelos profissionais de enfermagem do sexo masculino quanto à necessidade do ensino teórico-prático de enfermagem obstétrica foram:

- que se deve, em todo o ensino, aliar a teoria com a prática;

- que precisaram atuar em situações de urgência;

- que orientaram os atendentes;

- que devem assumir responsabilidades junto a sua família, como futuro pai ou como pai;

- que são solicitados pela vizinhança ou pelos serviços comunitários.

Além disso, eles expressaram que se sentem "moralmente" preparados para atender pacientes do sexo feminino.

Houve, também, a opinião de um auxiliar de enfermagem que só sentiu a utilidade do ensino quando em atividade profissional.

Comparando-se as razões apontadas pelos profissionais e pelas escolas, verifica-se que elas coincidem, quanto à necessidade do ensino teórico-prático.

\section{CONCLUSÃO}

Do exposto conclui-se que:

1 - não há uma filosofia única no ensino de enfermagem obstétrica para estudantes do sexo masculino; 
2- há três tendências neste ensino:

- o ensino deve ser teórico-prático;

- apenas teórico;

— ele não é necessário;

3 - estas tendências estão apoiadas mais em opiniões individuais de docentes e em situações locais de cada escola, do que em estudos de sua utilidade para os profissionais de enfermagem, nos três níveis;

4 - os profissionais de enfermagem (enfermeiros e auxiliares) inquiridos ressaltaram a necessidade dos conhecimentos adquiridos nessa disciplina;

5 - as razões para o ensino teórico-prático baseiam-se:

- na necessidade de um preparo completo dos profissionais de enfermagem nos três níveis;

- na utilidade deste ensino em situações de urgência;

- na necessidade de orientação do pessoal leigo de enfermagem;

6 - as razões para a omissão do ensino estão se baseando, sobretudo, na tradição.

\section{SUGESTÕES}

1 - que se realize um estudo de maior amplitude entre os profissionais de enfermagem do sexo masculino, nos três níveis, a fim de se investigar o que eles sentem em relação a utilidade desse ensino, agora, que já estão na prática profissional;

2 - que se investigue o grau de aceitação ou rejeição por parte das pacientes atendidas por estudantes do sexo masculino.

\section{REFERENCIAS BIBLIOGRÁFICAS}

1 - Why not obstetric nursing for male students? The Canadian Nurse, 62(10), 40-41, october 1966.

2 - ASSOCIAÇÃO BRASILEIRA DE ENFERMAGEM. Levantamento de Recursos e Necessidades de Enfermagem, 1959. Apostila mimeografada. 